\title{
Temperature Field Distribution of a Dissected Blast Furnace
}

\author{
Lei ZHANG, ${ }^{1)}$ Jianliang ZHANG, ${ }^{1,3) *}$ Haibin $\mathrm{ZUO}^{21}$ and Kexin $\mathrm{JIAO}^{1)}$ \\ 1) School of Metallurgical and Ecological Engineering, University of Science and Technology Beijing, Beijing, 100083 China. \\ 2) State Key Laboratory of Advanced Metallurgy, University of Science and Technology Beijing, Beijing, 100083 China. \\ 3) School of Chemical Engineering, The University of Queensland, St Lucia, QLD, 4072 Australia.
}

(Received on November 9, 2018; accepted on January 8, 2019; J-STAGE Advance published date: March 11, 2019)

\begin{abstract}
The temperature field distribution of the upper part of a blast furnace (BF) is the result of the combination of charge distribution and gas flow. It is of great significance for both researchers and operators to study the thermal state and the phenomenon of the BF. The graphite box method is used in this study to obtain the temperature field distribution in the upper part of a $125 \mathrm{~m}^{3}$ BF. Graphite boxes with a variety of different melting point metals were loaded into the BF with the charge. And the temperature field distribution was obtained after the boxes were taken out with position and temperature information during the dissection process. The results illustrate that the graphite boxes are unevenly distributed in the BF, which was related to the distribution of BF materials. Furthermore, the temperature field distribution is asymmetric, and the isotherms present an irregular "W" shape, which is caused mainly by the simultaneous development of the edge airflow and the central airflow. Moreover, the shape of the softening and melting zone observed in the dissection process has a good correspondence with the temperature field. We concluded that the deflection of the temperature field and the softening and melting zone is related to the strong gas flow in the direction of No. 3 tuyere, the existence of accretion in the hearth, and the filling of refractory materials in tuyeres before blowing out.
\end{abstract}

KEY WORDS: dissection of blast furnace; graphite box method; temperature field distribution; softening and melting zone.

\section{Introduction}

The blast furnace $(\mathrm{BF})$ has been thought to be the largest and most complex reactor in the ironmaking process. It is a counter-current moving bed chemical reactor, involving multiphase flow reaction, complex oxidation and reduction reactions, and irregular physical changes with the temperature increases. ${ }^{1,2)}$ In general, the internal conditions of BF are very complicated and difficult to be obtained by the operators. Over recent years, a number of attempts have been made in order to understand the inner conditions of $\mathrm{BF}$, including the dissection of BF after blowing out, ${ }^{3,4)}$ the experimental research in the laboratory, ${ }^{5-8)}$ and the numerical simulation methods. ${ }^{9-14)}$ Among them, the dissection method is considered to be the most accurate method as it obtains the information directly from an actual produced BF.

The temperature distribution is very important in blast furnace production process because it is related to the distribution of gas flow and reflects the thermal state in BF which will determine the energy utilization and consumption. Moreover, the temperature field distribution is an important basis for studying the starting temperature of a specific reaction, as well as the products at a certain temperature. In the

\footnotetext{
* Corresponding author: E-mail: zhang.jianliang@hotmail.com. DOI: https://doi.org/10.2355/isijinternational.ISIJINT-2018-753
}

past few decades, Japan has carried out dissection studies on several BFs from the late 1960 s to the 1980 s, ${ }^{15}$ and China also carried out the BF dissection investigation for the first time in a $23 \mathrm{~m}^{3}$ test $\mathrm{BF}$ in $1979,{ }^{16)}$ and then a $0.8 \mathrm{~m}^{3}$ test $\mathrm{BF}$ in 1982. However, many research details and conclusions have not been reported, especially the temperature field distribution in the $\mathrm{BF}$.

In recent years, many researchers pay more attention to the hearth erosion, ${ }^{17)}$ the refractory reaction, ${ }^{18)}$ the slag performance, ${ }^{19)}$ and the damage of cooling staves, ${ }^{20)}$ etc. With the advancement of technology and equipment, the requirements of high efficiency, longevity and low consumption, the development of large-scale blast furnace has become a trend, which will lead to a dramatic increase in the workload of a study of upper part of a BF. Nevertheless, the $\mathrm{BF}$ always releases the residual iron and the charge also drops to a very low level in most dissection process. To the best of the author's present knowledge, there are few studies were carried out on the temperature field distribution during a dissection process.

In this work, the dissection study was carried out on a 125 $\mathrm{m}^{3} \mathrm{BF}$, which focusd on the use of the graphite box method to obtain the temperature field distribution of the upper part the BF. It is the first time to study the temperature field distribution of a produced BF in China. The temperature field distribution is of great significance for studying the charge structure, as well as the distribution of air flow. It can also 
deepen the understanding of the relevance of BF operation to phenomenon.

\section{Investigation Method}

\subsection{Overview of the Blast Furnace}

The effective volume of the BF is $125 \mathrm{~m}^{3}$, and the structure of the BF is shown in Fig. 1(a). The basic information

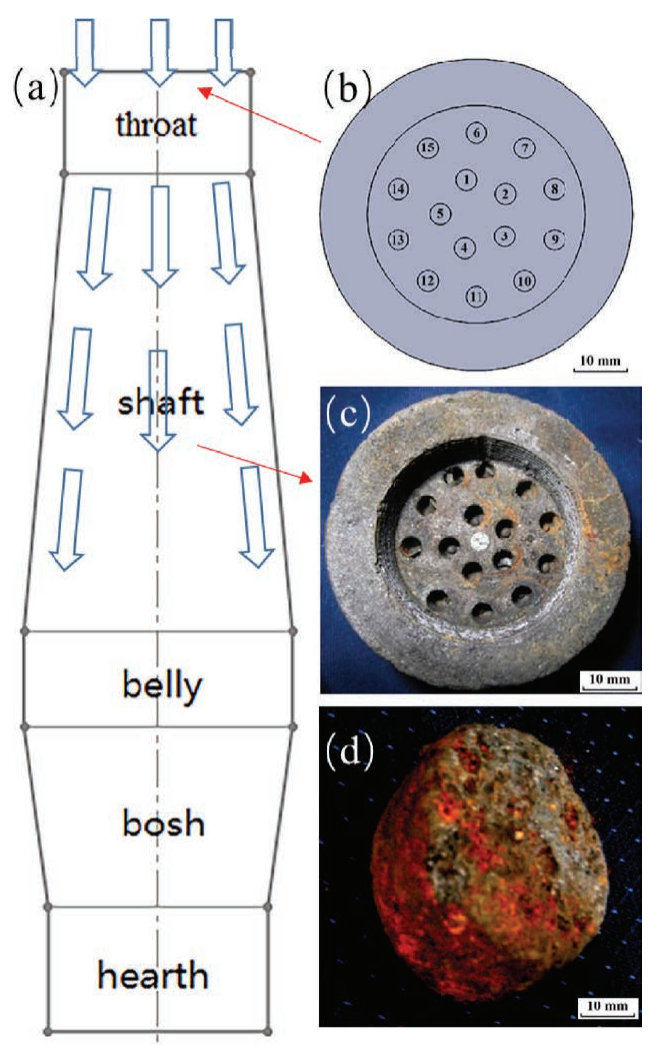

Fig. 1. The schematic diagram of $\mathrm{BF}$ and graphite box. (Online version in color.) of the BF which has been designed is as following: the hearth diameter is $3.2 \mathrm{~m}$, the belly diameter is $3.9 \mathrm{~m}$, and the throat diameter is $2.7 \mathrm{~m}$. The BF has one tap hole, one slag hole and eight tuyeres. The relevant parameters are listed in Table 1.

The BF was water-quenched from the top. The initial water consumption rate is set to $7.8 \mathrm{t} / \mathrm{h}$ and it will be adjusted by the amount of gas exhausted from slag holes. The cooling process lasted for 6 days until the water temperature dropped down to 24 degrees and the total water consumption is 602 tons. During the cooling process, No. 3 and No. 4 tuyeres were filled with refractory material to maintain the original appearance. The production data for the last three days before blowing out were listed in Table 2.

\subsection{Graphite Box Method}

Graphite boxes with a variety of different melting point metals were added to the BF with the charging process. The furnace was immediately blow out when the first batch of graphite boxes arrived the lower part of the furnace. During the dissection process, graphite boxes were taken out, numbered and recorded with the location information as well. The boxes were opened in the laboratory when they were cooled down, and then the temperature information wes recorded by observing the melting condition of metal sheets inside the box.

The graphite box is made of a special container with a screw cap which is designed to have the characteristics of high temperature strength. And it also designed to have an outer diameter of $60 \mathrm{~mm}$, a height of $48 \mathrm{~mm}$, a wall thickness of $9 \mathrm{~mm}$, and 15 holes for metal placement. As a result, it will have a character of small volume, sufficient temperature measurement range and sufficient strength as well. Thus, the boxes can exist completely in any part (except for the raceway) just like coke, and measure the temperature there. The structure of graphite box is shown as Fig. 1(b).

Table 1. The structure parameters of BF.

\begin{tabular}{cccccc}
\hline Parameter & Unit & Value & Parameter & Unit & Value \\
\hline Effective volume & $\mathrm{m}^{3}$ & 124.87 & Furnace belly diameter & $\mathrm{mm}$ & 3900 \\
Effective height & $\mathrm{mm}$ & 14150 & Furnace hearth diameter & $\mathrm{mm}$ & 3200 \\
Furnace hearth height & $\mathrm{mm}$ & 1850 & Angle of bosh & degree & $82^{\circ} 28^{\prime} 34^{\prime \prime}$ \\
Furnace bosh height & $\mathrm{mm}$ & 2650 & Angle of furnace body & degree & $84^{\circ} 55^{\prime} 13^{\prime \prime}$ \\
Furnace belly heigh & $\mathrm{mm}$ & 1400 & Charging bell diameter & $\mathrm{mm}$ & 1550 \\
Furnace body heigh & $\mathrm{mm}$ & 6750 & Tuyere number & - & 8 \\
Furnace throat height & $\mathrm{mm}$ & 1500 & Taphole number & - & 1 \\
Throat diameter & $\mathrm{mm}$ & 2700 & Slag hole number & - & 1 \\
\hline
\end{tabular}

Table 2. The production data for the last three days before blowing out.

\begin{tabular}{|c|c|c|c|c|c|c|c|}
\hline Date & $\begin{array}{l}\text { Daily output/ } \\
\qquad \cdot \mathrm{d}^{-1}\end{array}$ & $\begin{array}{c}\text { Coal ratio/ } \\
\mathrm{kg} \cdot \mathrm{t}^{-1}\end{array}$ & $\begin{array}{c}\text { Coke ratio/ } \\
\mathrm{kg} \cdot \mathrm{t}^{-1}\end{array}$ & $\begin{array}{l}\text { Utilization } \\
\text { coefficient/ } \\
\mathrm{t} . \mathrm{m}^{-3} \cdot \mathrm{d}^{-1}\end{array}$ & $\begin{array}{l}\text { Combustion } \\
\text { intensity/ } \\
\mathrm{t} \cdot \mathrm{m}^{-3} \cdot \mathrm{d}^{-1}\end{array}$ & $\begin{array}{l}\text { Coke } \\
\text { load }\end{array}$ & $\begin{array}{c}\text { Furnace base } \\
\text { temperature } /{ }^{\circ} \mathrm{C}\end{array}$ \\
\hline 20071215 & 450 & 64 & 433 & 3.75 & 1.63 & 3.35 & $257 / 390$ \\
\hline 20071216 & 450 & 57 & 435 & 3.75 & 1.63 & 3.36 & $262 / 396$ \\
\hline 20071217 & 360 & 78 & 539 & 3.00 & 1.62 & 3.31 & $262 / 398$ \\
\hline
\end{tabular}


Table 3. The parameters of metal sheets for temperature measurement.

\begin{tabular}{cccccc}
\hline Number & Element & $\begin{array}{c}\text { Melting } \\
\text { point } /{ }^{\circ} \mathrm{C}\end{array}$ & Number & Element & $\begin{array}{c}\text { Melting } \\
\text { point } /{ }^{\circ} \mathrm{C}\end{array}$ \\
\hline 1 & $\mathrm{~Pb}$ & 420 & 9 & $\mathrm{Ni}-\mathrm{Cu}-7$ & 1140 \\
2 & $\mathrm{P}$ & 470 & 10 & $\mathrm{Ni}-\mathrm{Cu}-6$ & 1160 \\
3 & $\mathrm{Zn}$ & 490 & 11 & $\mathrm{Ni}-\mathrm{Cu}-5$ & 1200 \\
4 & $\mathrm{Al}$ & 730 & 12 & $\mathrm{Ni}-\mathrm{Cu}-4$ & 1280 \\
5 & $\mathrm{Cu}-\mathrm{Hs} 222$ & 950 & 13 & $\mathrm{Ni}-\mathrm{Cu}-3$ & 1350 \\
6 & $\mathrm{Cu}-\mathrm{H} 80$ & 980 & 14 & $\mathrm{Ni}-\mathrm{Cu}-2$ & 1380 \\
7 & $\mathrm{Cu}$ & 1040 & 15 & $\mathrm{Ni}-\mathrm{Cu}-1$ & 1420 \\
8 & $\mathrm{Ni}-\mathrm{Cu}-8$ & 1090 & & & \\
\hline
\end{tabular}

The composition and melting point of the metal pieces in the graphite box are shown in Table 3 (the temperature was calibrated first). As the charge moves downward, the temperature measuring piece in the box melts one by one. The deformation of the inside metal reflects the temperature at the location of the graphite box.

\section{Results and Discussion}

\subsection{The Distribution of Graphite Boxes}

In this study, 420 graphite boxes were put into the BF with the charging process, and 325 boxes were finally founded and recovered during the sampling process. We opened a total of 243 graphite boxes in the laboratory, of which 25 boxes were unable to obtain temperature data due to the destruction and operational reasons. So the effective data number of position and temperature are 325 and 218 respectively. The appearance of the graphite box and the melting and deformation condition of the metal sheets inside the box are shown in the Figs. 1(c) and 1(d). The temperature is determined by the highest melting point of all the melted metal sheets, it usually adjacent to an unmelted metal piece if it is not the $\mathrm{Ni}-\mathrm{Cu}-1$ alloy which has the highest melting point of all the fifteen kinds of metals. The temperature range between metals with different melting points is ignored. Statistics were performed on 325 samples location information, including height direction distribution and circumferential distribution. The statistical results are shown in the Fig. 2.

As shown in Fig. 2, the graphite boxes are mostly distributed in the range of 6-9 $\mathrm{m}$ in height from top surface of burden to the belly of BF. The coke and ore present a layered structure in the BF. With the charge moving down, the temperature rises, the ore gradually melts, and some of the coke is also consumed as well. Thus the layered structure becomes thinner, and more layers of coke are deposited in this area. At the same time, the movement becomes slower at this part of BF. So more boxes were gathered in the middle part of $\mathrm{BF}$.

As shown in Fig. 3, there are 205 graphite boxes on the side of No. 1 tuyere $\rightarrow$ No. 3 tuyere $\rightarrow$ No. 5 tuyere, accounting for $63 \%$ of the total number. And on the other side, there are 120 graphite boxes, accounting for $37 \%$ of the total. The unevenly distributed of the boxes has a good correspondence with the top surface shape of the charging

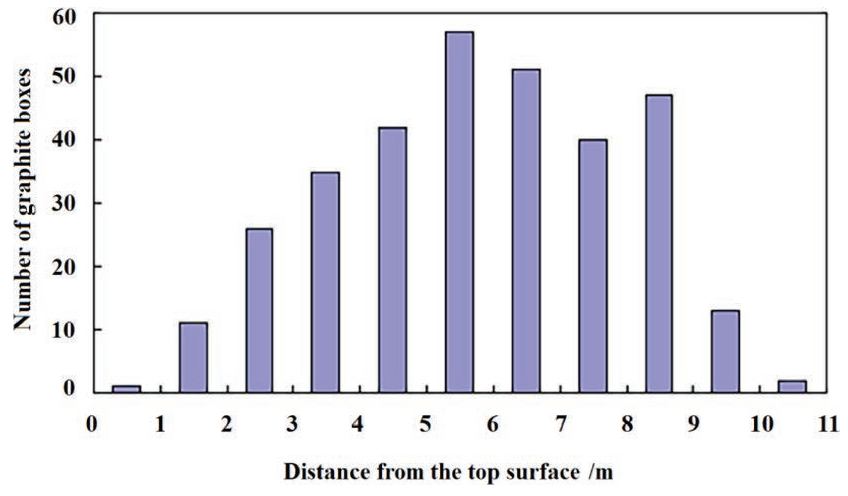

Fig. 2. The distribution of 325 samples in the height direction. (Online version in color.)

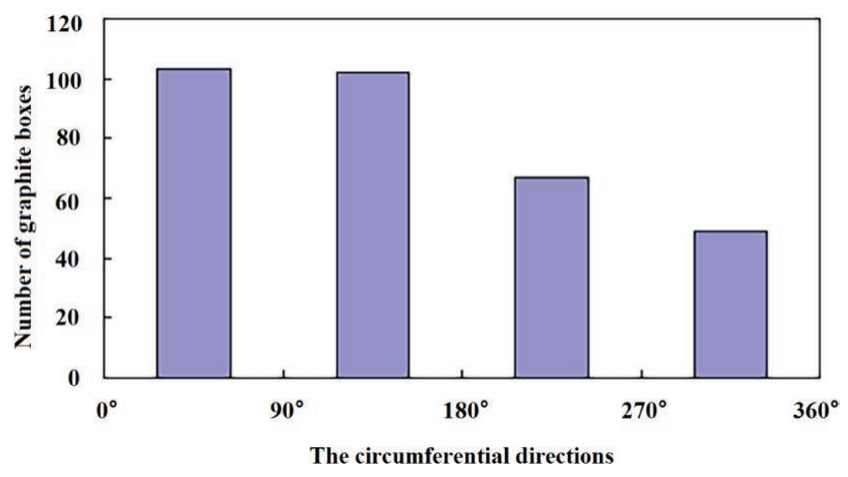

Fig. 3. The distribution of 325 samples in the circumferential direction. (Online version in color.)
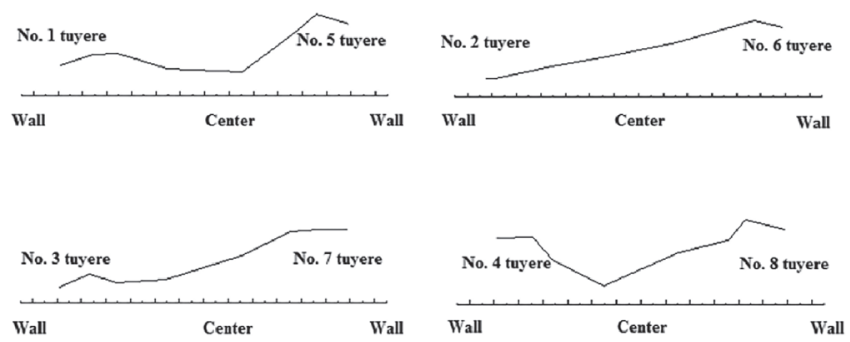

Fig. 4. The shape of the top surface of the BF.

materials. Figure 4 shows the top surface shape of the BF in four vertical sections.

As shown in Fig. 4, four vertical sections of top surface shape are measured during the process of dissection. The material surface is obviously lower in the direction of No. 1 tuyere, No. 2 tuyere, and No. 3 tuyere, especially in the direction of No. 2 tuyere, there is only one peak exist in the polyline. Therefore, even without considering the influences of the bell-type distributor itself, the coke will roll toward to the lower surface after being loaded into the BF, especially the graphite box, which has a more regular shape with better rolling performance. The top surface shape was also influenced by the upturn of throat brick and the existence of the accretion in the BF, which causes the abnormal distribution and the unevenly descending of charge.

\subsection{The Temperature Field Distribution in Blast Fur- nace}

Statistics were also performed on 218 samples temperature information along the height direction. The result is 
shown in the Fig. 5.

It can be seen from the figure that the temperature distribution can be divided into three regions. The first region: 0-7 $800 \mathrm{~mm}$. In this area, the temperature range is mainly changes from $400^{\circ} \mathrm{C}$ to $500^{\circ} \mathrm{C}$, and some individual temperature reaches $730^{\circ} \mathrm{C}$, which is caused by the partial airflow. This is the low temperature zone above the thermal reserve zone $\left(950^{\circ} \mathrm{C}-1000^{\circ} \mathrm{C}\right)$. The second region: $7800-11000$ $\mathrm{mm}$. The temperature difference in this area, both the highest temperature and the lowest temperature appears here. It can be preliminarily believed that the thermal reserve zone and softening zone mainly exist in this area. The third region: $11000-14000 \mathrm{~mm}$. The temperature in this area is high and mainly between $1100^{\circ} \mathrm{C}$ and $1400^{\circ} \mathrm{C}$. This area can be considered as the root of the softening and melting zone.

Figure 6 shows the temperature field distribution in the direction of No. 1 tuyere-No. 5 tuyere and No. 3 tuyere-No. 7 tuyere respectively. The isotherms are calculated by the measurement data obtained from graphite box. Firstly, the

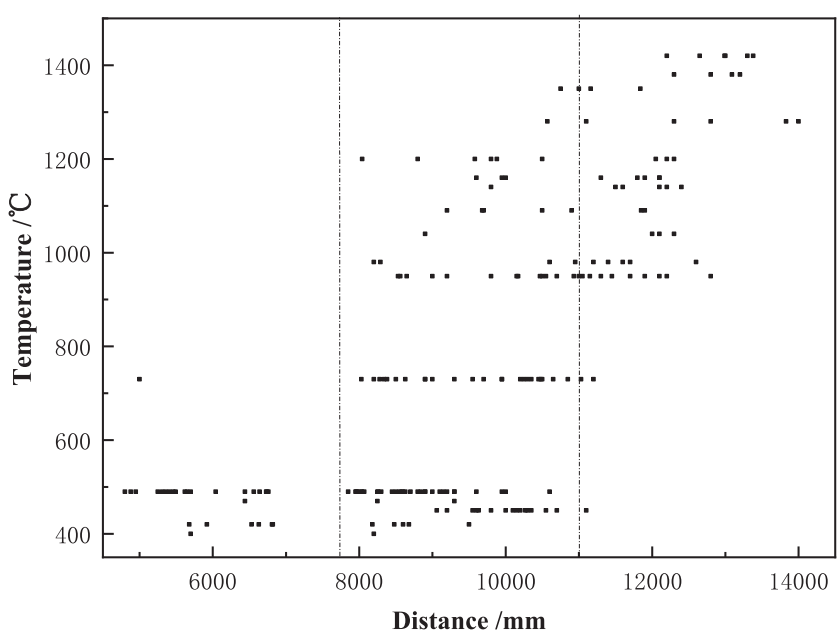

Fig. 5. The statistics result of temperature in the height direction.

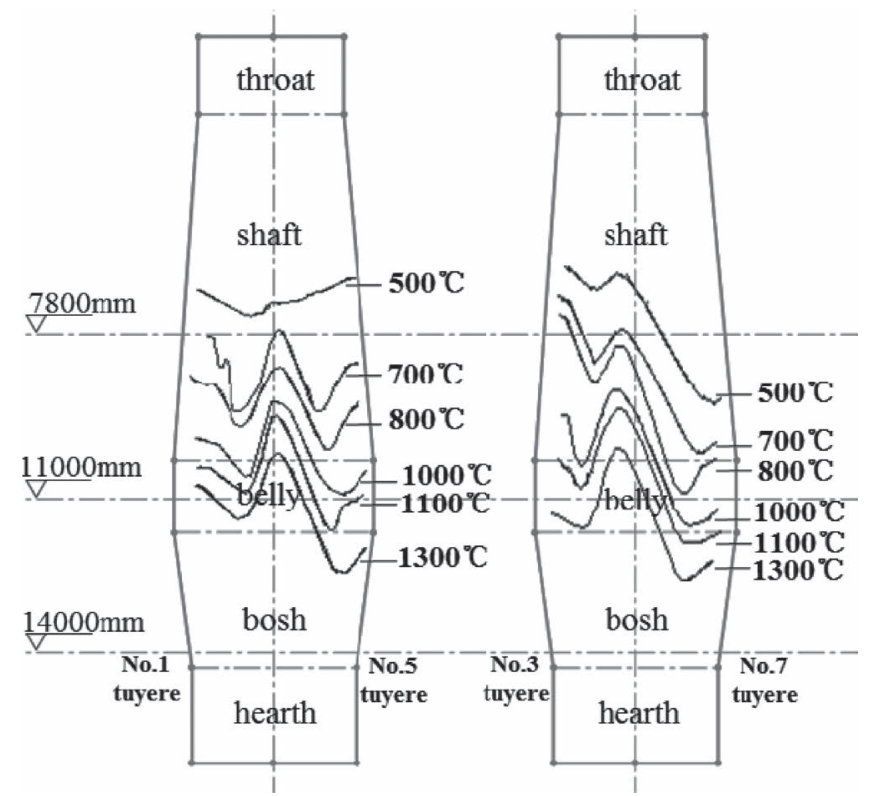

Fig. 6. The temperature field distribution in different tuyere directions. inner section of the BF was divided into grids according to the height and radial length. Secondly, the temperature data were loaded onto the nodes and the abnormal temperature points were removed. Then, the temperature of all the main nodes were calculated from surrounding data by linear differential methods. Finally, the nodes with same temperature were connected into a curve, the isotherms were obtained. It can be seen from the left half of Fig. 6 that the temperature curve is basically "W" type, which is caused by the simultaneous development of the edge airflow and the central airflow. And the temperature curve is asymmetrical. At the same elevation, the temperature in the direction of the No. 1 tuyere is generally slightly higher than the temperature in the direction of the No. 5 tuyere. This is because the airflow on the side of the No. 1 tuyere wall is more developed than that on the No. 5 tuyere side, thereby resulting in a relatively dense isotherms in the area.

It can be seen from the right half of Fig. 6 that the temperature curve is irregular "W" type, and at the same elevation, the temperature in the direction of the No. 3 tuyere is obviously higher than the temperature in the direction of the No. 7 tuyere. The isotherms rise on the side of the No. 3 tuyere, which indicats that the airflow in the direction of the No. 3 tuyere is more developed. It is consistent with the daily production phenomenon observed by the operators.

The irregular "W" type of the isotherm is also related to the top surface shape shown in Fig. 4. When there are less charge in the direction of No. 1 to No. 3 tuyere, there will be less resistance when the gas flow pass through.

\subsection{The Distribution of Softening and Melting Zone in Blast Furnace}

During the dissection process, the position information of the softening and melting zone is obtained with the sampling progress. Draw it together with the BF isotherm map, the results are shown in Fig. 7.

The softening and melting zone presents an irregular inverted "V" shape. It has a height of about $5000 \mathrm{~mm}$, and

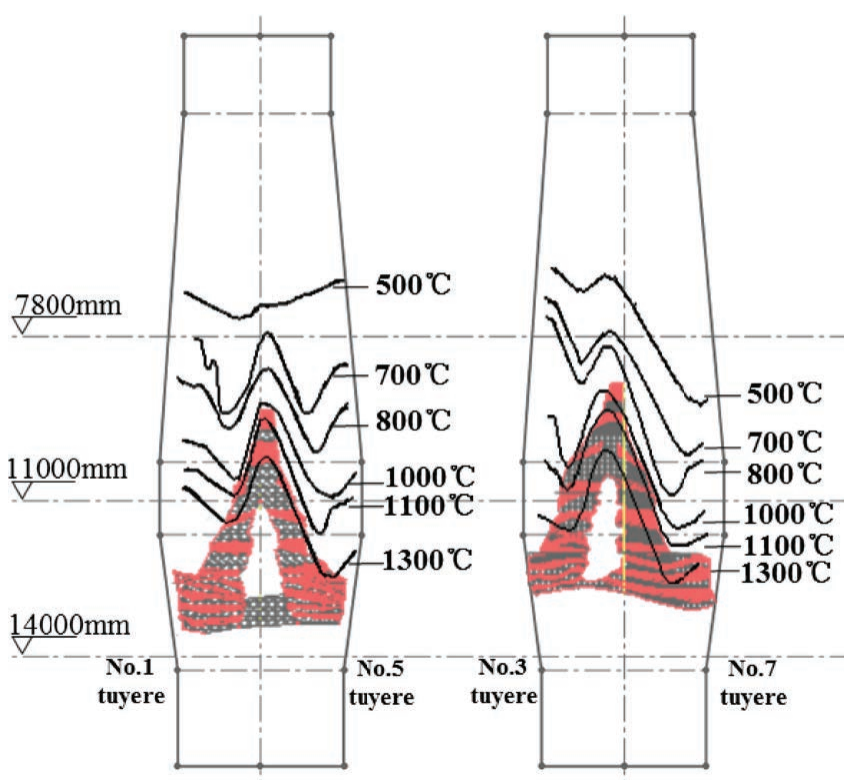

Fig. 7. Distribution map of BF softening and melting zone in different tuyere directions. (Online version in color.) 
a diameter of about $3600 \mathrm{~mm}$ at the bottom, and the ratio of height to diameter is 1.38 . It can be seen that the shape of softening and melting zone has a good correspondence with the temperature field. What's more, the whole softening and melting zones maintain the layered structure as same as in the lumpy zone, and even in the lower part, there are some very thin interlayers exist. The angle of inclination of the layered structure becomes smaller, for the charge at the edge of BF fell quicker because of the consumption of coke at the tuyere position. What's more, there is a $200-300 \mathrm{~mm}$ unbonded region between the bottom of the softening and melting zone and the furnace wall, where the airflow can be easily passed through.

The softening and melting zone is layered, shown as Fig. 8(a). The direction of tuyere is shown as Fig. 8(b). The cross-sectional of each layer in different directions from top to bottom is shown in the Fig. 8(c). It can be seen that the cross-sectional area of the reflow zone is constantly expanding. And the center is inclined to the side of No. 3 tuyere, which is related to the development of the gas flow here.

In addition, during the dissection of the BF, it was also found that the accretion mainly exists on the directions of No. 2 tuyere to No. 4 tuyere. It is shown in Fig. 9(a) that there is a accretion under the throat of the furnace in the
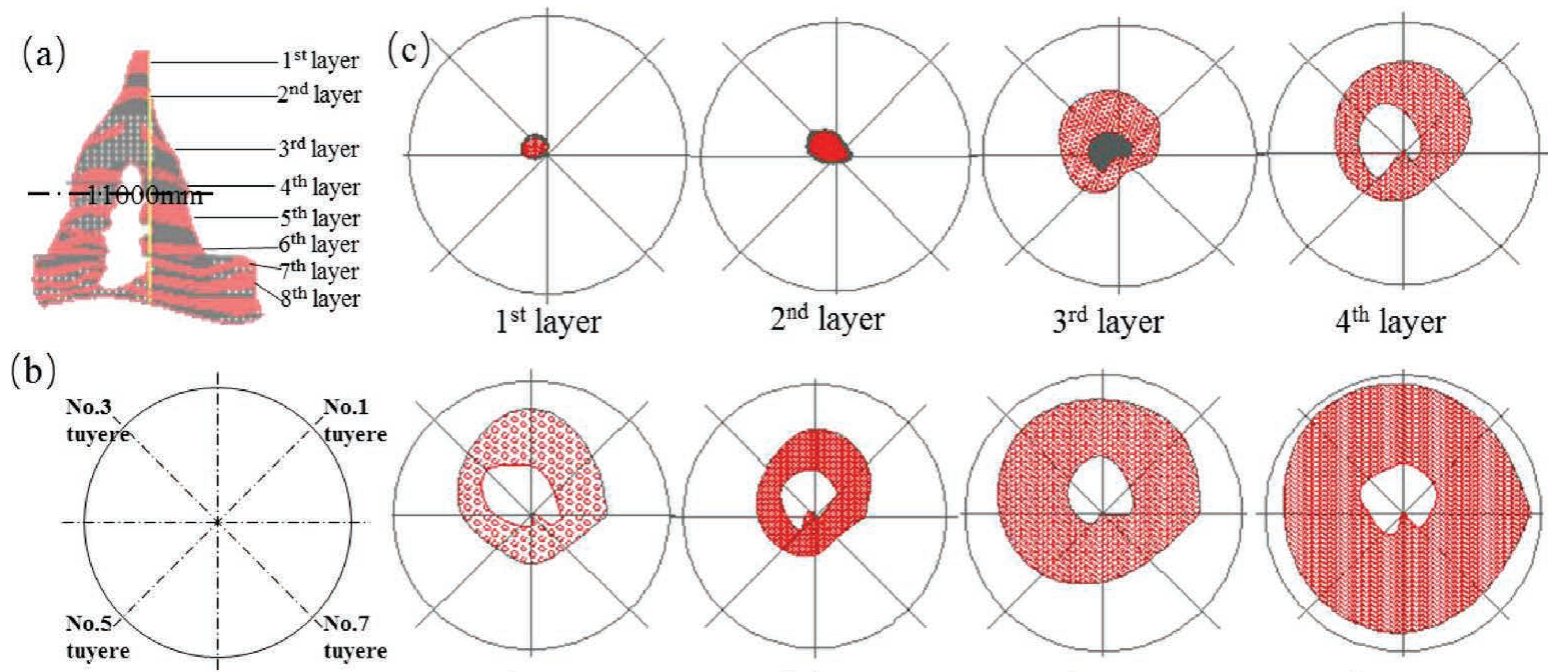

$3^{\text {rd }}$ layer

$4^{\text {th }}$ layer

$5^{\text {th }}$ layer

$6^{\text {th }}$ layer

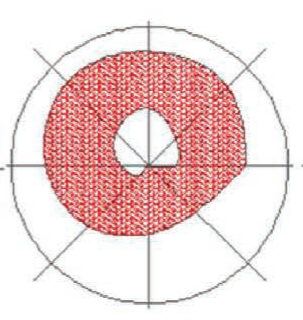

$7^{\text {th }}$ layer

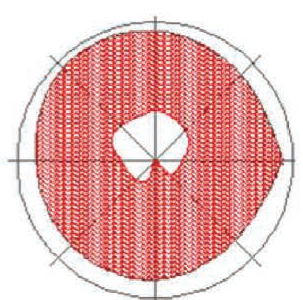

$8^{\text {th }}$ layer

Fig. 8. Cross-section of each layer of softening and melting zone. (Online version in color.)

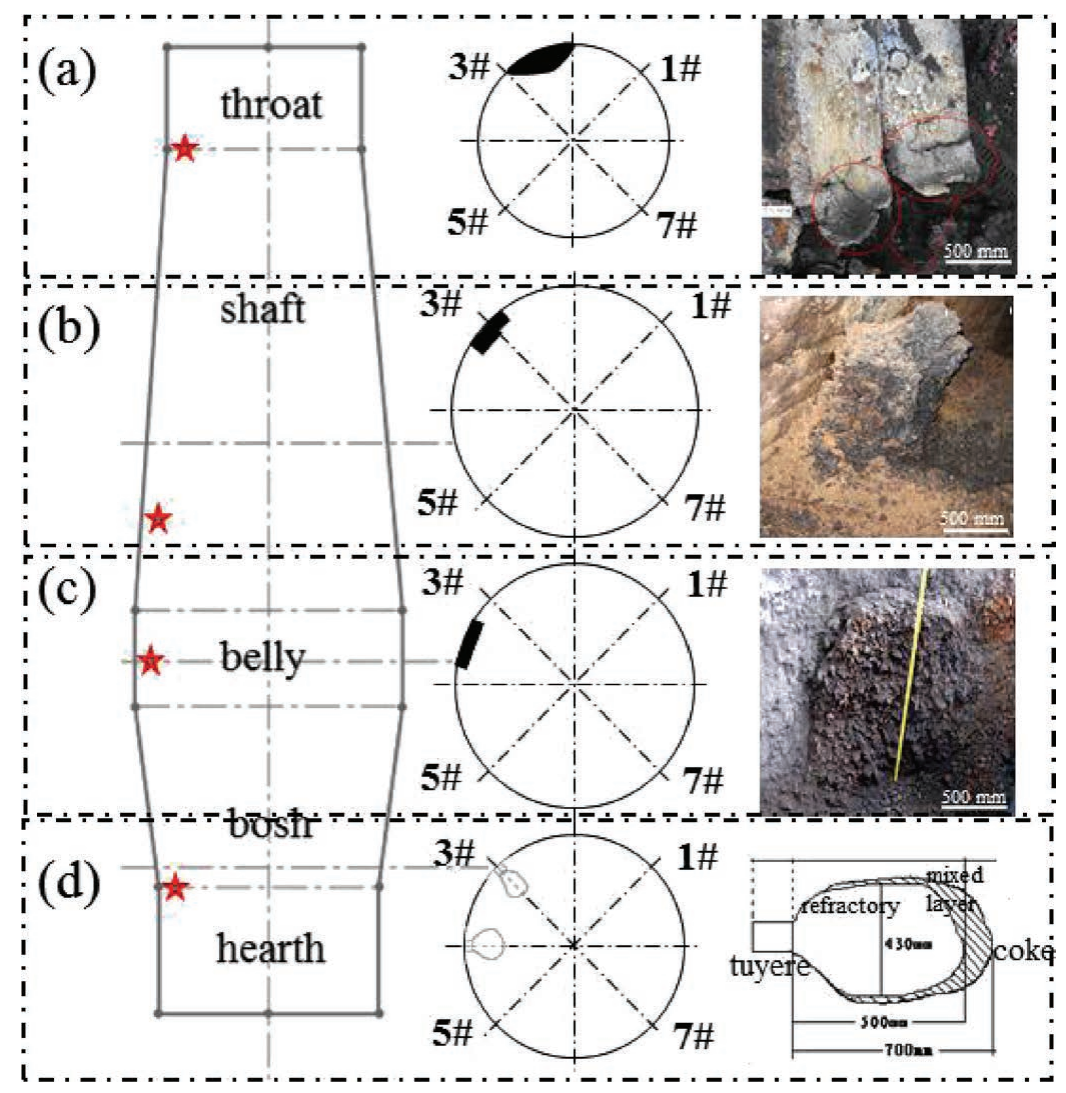

Fig. 9. Schematic diagram and pictures of different positions inside the blast furnace. (Online version in color.) 
direction of No. 2 tuyere, which works with the upturn of the throat brick to obstruct the movement of the charge and causes the material surface to be a lower level. Figure 9(b) indicates that there is also a large accretion exists in the middle of the furnace body of the direction of No. 3 tuyere, it can be thought as being merged by two pieces, with the size of $300 \mathrm{~mm} \times 500 \mathrm{~mm} \times 400 \mathrm{~mm}$ and $200 \mathrm{~mm} \times 300 \mathrm{~mm} \times$ $200 \mathrm{~mm}$ respectively. In addition, a large accretion was also found in belly between the directions of No. 3 tuyere and No. 4 tuyere, which is tightly integrated with the furnace wall, and has the size of $1200 \mathrm{~mm} \times 1300 \mathrm{~mm} \times 200 \mathrm{~mm}$, shown as Fig. 9(c). It can be considered that the accretion changes the movement of the charge and affects the distribution of the gas flow, and it is one of the most important factors that cause the strong gas flow at the No. 3 tuyere direction. In addition, before the furnace was blow out, the No. 3 tuyere and No. 4 tuyere were filled with refractory materials. The size of raceway formed by the No. 4 tuyere was shown in Fig. 9(d). The refractory material maintains the shape of the raceway well. To a certain degree, it affects the distribution of the softening and melting zone during the dissection process by supporting the upper materials, which will result in a high position of softening and melting zone in the direction of No. 3 and No. 4 tuyere.

\section{Conclusions}

In this paper, the temperature field distribution of the $\mathrm{BF}$ was studied by the graphite box method. The graphite boxes ,containing 15 kinds of metals with difference melting points, were charged into BF before blow out, and then taken out during dissection process to obtain the temperature and location information. The shape of softening and melting zone was also analyzed. The results show that:

(1) The graphite boxes are unevenly distributed in the BF. There are more graphite boxes on the side of No. 1 tuyere $\rightarrow$ No. 3 tuyere $\rightarrow$ No. 5 tuyere, accounting for $63 \%$ of the total, for the material surface is obviously lower in those directions.

(2) The temperature field distribution in the cross-section of No. 1 tuyere $\rightarrow$ No.5 tuyere and No. 3 tuyere $\rightarrow$ No. 7 tuyere was plotted. The isotherms present an irregular "W" shape, where the temperature in the direction of the No. 1 and No. 3 tuyere is higher, indicating that the airflow in those directions is more developed, especially in the direction of No. 3 tuyere. The result is consistent with daily records;

(3) The shape of the softening and melting zone founded in the dissection process has a good correspondence with the temperature field. The cross-sectional area of the softening and melting zone is constantly expanding from top to bottom, and the center is inclined to the side of No. 3 tuyere. The deflection in the distribution of the softening and melting zone is mainly related to the strong gas flow in the No. 3 tuyere direction, and the accretion in the hearth, and the filling of refractory materials before stopping the furnace.

\section{Acknowledgements}

This work was financially supported by the National Science Foundation for Young Scientists of China (51704019), Major Science and Technology Program for Water Pollution Control and Treatment (2017ZX07402001), the Fundamental Research Funds for the Central Universities (FRF-BD-17-010A and FRF-TP-17-040A1).

\section{REFERENCES}

1) D. Fu, Y. Chen, Y. Zhao, J. D'Alessio, K. J. Ferron and C. Q. Zhou: Appl. Therm. Eng., 66 (2014), 298.

2) Q. Li, P. Gao, B Liu, M. Feng and Z. Zou: Baosteel Biennal Academic Conf. (Baosteel BAC), Metallurgical Industry Press, Beijing, (2013), 1.

3) A. Shinotake, H. Nakamura, N. Yadoumaru, Y. Morizane and M. Meguro: ISIJ Int., 43 (2003), 321.

4) T. Inada, A. Kasai, K. Nakano, S. Komatsu and A. Ogawa: ISIJ Int., 49 (2009), 470.

5) K. X. Jiao, J. L. Zhang, Z. J. Liu, M. Xu and F. Liu: Int. J. Miner. Metall. Mater., 22 (2015), 1017.

6) J. L. Zhang, K. X. Jiao, Z. J. Liu and T. J. Yang: Iron Steel, 52 (2017), No. 12, 1 (in Chinese).

7) X. Y. Fan, K. X. Jiao, J. L. Zhang, K. D. Wang and Z. Y. Chang: ISIJ Int., 58 (2018), 1775.

8) K. X. Jiao, J. L. Zhang, Z. J. Liu, S. Kuang and Y. X. Liu: ISIJ Int., 57 (2017), 48.

9) J. Yagi: ISIJ Int., 33 (1993), 619

10) P. R. Austin, H. Nogami and J. Yagi: ISIJ Int., 37 (1997), 748

11) J. A. Castro, H. Nogami and J. Yagi: ISIJ Int., 40 (2000), 637.

12) H. Kawai and H. Takahashi: ISIJ Int., 44 (2004), 1140.

13) X. F. Dong, A. B. Yu, J. Yagi and P. Zulli: ISIJ Int., 47 (2007), 1553.

14) M. Tsuboi and K. Ito: ISIJ Int., 57 (2017), 1191.

15) L. B. Li: Ironmaking, 05 (1986), 58 (in Chinese).

16) J. H. Zhu: Iron Steel, 11 (1982), 1 (in Chinese).

17) K. X. Jiao, J. L. Zhang, Z. J. Liu, C. L. Chen and Y. X. Liu: ISIJ Int., 56 (2016), 1956.

18) K. X. Jiao, X. Y. Fan, J. L. Zhang, K. D. Wang and Y. A. Zhao: Ceram. Int., 44 (2018), 19981.

19) K. X. Jiao, J. L. Zhang, C. L. Chen and Y. X. Liu: ISIJ Int., 56 (2016), 1956.

20) H. Zhang, K. X. Jiao, J. L. Zhang and J. P. Liu: Mater. Des., 154 (2018), 140. 